\title{
The Case for Using the General Linear Model as a Unifying Conceptual Framework for Teaching Statistics and Psychometric Theory
}

\author{
Bruce Thompson \\ Texas A\&M University and Baylor College of Medicine
}

\begin{abstract}
The present paper argues for teaching statistics and psychometric theory using the GLM as a unifying conceptual framework. This helps students understand what analyses have in common, and also provides a firm grounding for understanding that more general cases of the GLM (canonical correlation analysis and SEM) can be interpreted with the same rubric used throughout the GLM. And this approach also helps students better understand analyses that are not part of the GLM, such as predictive discriminant analysis (PDA). The approach helps students understand that all GLM analyses (a) are correlational, and thus are all susceptible to sampling error, (b) can yield $r^{2}$-type effect sizes, and (c) use weights applied to measured variables to estimate the latent variables really of primary interest.
\end{abstract}

Keywords: General Linear Model, significance testing, effect sizes

In a very influential APA presidential address in the late 1950s, Lee Cronbach advocated greater use of aptitude-treatment interaction designs, and effectively decried the then common misconception that statistics could be conceptualized as fitting within two classes: experimental statistics and correlational statistics. But not much happened with respect to how researchers conceptualized and taught statistics and psychometrics.

Then, in 1968, Cohen published a seminal article that was almost as important as his 1994 article, "The Earth is round $(p<.05)$." In the 1968 article, Cohen said, although he thought most statisticians would find his argument obvious, most psychologists at the time on the other hand had no idea that regression subsumed ANOVA and other univariate analyses as special cases. Thus, regression is the univariate general linear model (GLM). He argued that the GLM was important conceptually, but also that very important advantages could be realized by using regression to conduct many univariate analyses.

Subsequently, Knapp (1978) showed that canonical correlation analysis (CCA; see Thompson, 1984, 2000) was the multivariate GLM, subsuming in addition to other multivariate methods (e.g., Hotelling $T^{2}$, descriptive discriminant analysis [but not predictive discriminant analysis], and MANOVA and MANCOVA) univariate regression and the other univariate parametric methods. Finally, Bagozzi, Fornell, and Larcker (1981; also see Fan, 1997) showed that structural equation modeling (SEM) was the most general case of the GLM. 
A virtual regression-discontinuity study of the influence of Cohen's article shows that the field changed dramatically following Cohen's (1968) publication. Studies by Edgington (1964, 1974) covering several decades showed that prior to the 1968 article around 2/3rds to 3/4ths of published articles used ANOVAs. Similar studies after the 1968 article showed a large drop in the use of ANOVAs (Elmore \& Woehlke, 1988; Goodwin \& Goodwin, 1985; Kieffer, Reese \& Thompson, 2001; Willson, 1980).

The present paper argues for teaching statistics and psychometric theory using the GLM as a unifying conceptual framework. This helps students understand what analyses have in common, and also provides a firm grounding for understanding that more general cases of the GLM (canonical correlation analysis and SEM) can be interpreted with the same rubric used throughout the GLM. And this approach also helps students better understand analyses that are not part of the GLM, such as predictive discriminant analysis (PDA). The approach helps students understand that all GLM analyses (a) are correlational, and thus are all susceptible to sampling error, (b) can yield $r^{2}$-type effect sizes, and (c) use weights applied to measured variables to estimate the latent variables really of primary interest.

\section{More on Defining the GLM}

The General Linear Model is the concept that "all analytic methods are correlational ... and yield variance-accounted-for effect sizes analogous to (e.g., $\left.R^{2}, \eta^{2}, \omega^{2}\right) "$ (Thompson, 2000, p. 263). As Graham (2008) explained,

The vast majority of parametric statistical procedures in common use are part of [a single analytic family called] the General Linear Model (GLM), including the $t$ test, analysis of variance (ANOVA), multiple regression, descriptive discriminant analysis (DDA), multivariate analysis of variance (MANOVA), canonical correlation analysis (CCA), and structural equation modeling (SEM). Moreover, these procedures are hierarchical [italics added], in that some procedures are special cases of others. (p. 485)

Figure 1 presents a conceptual map of the commonly used statistical analyses falling within the General Linear Model. As noted previously, predictive discriminant analysis (PDA), unlike descriptive discriminant analysis (DDA), is not part of the GLM (Huberty, 1994). It can also be shown that the mathematics of factor analysis are used to compute the multiplicative weights applied to the measured variables, either explicitly or implicitly, in all analyses throughout the GLM. 
Figure 1. Conceptual Map of the General Linear Model

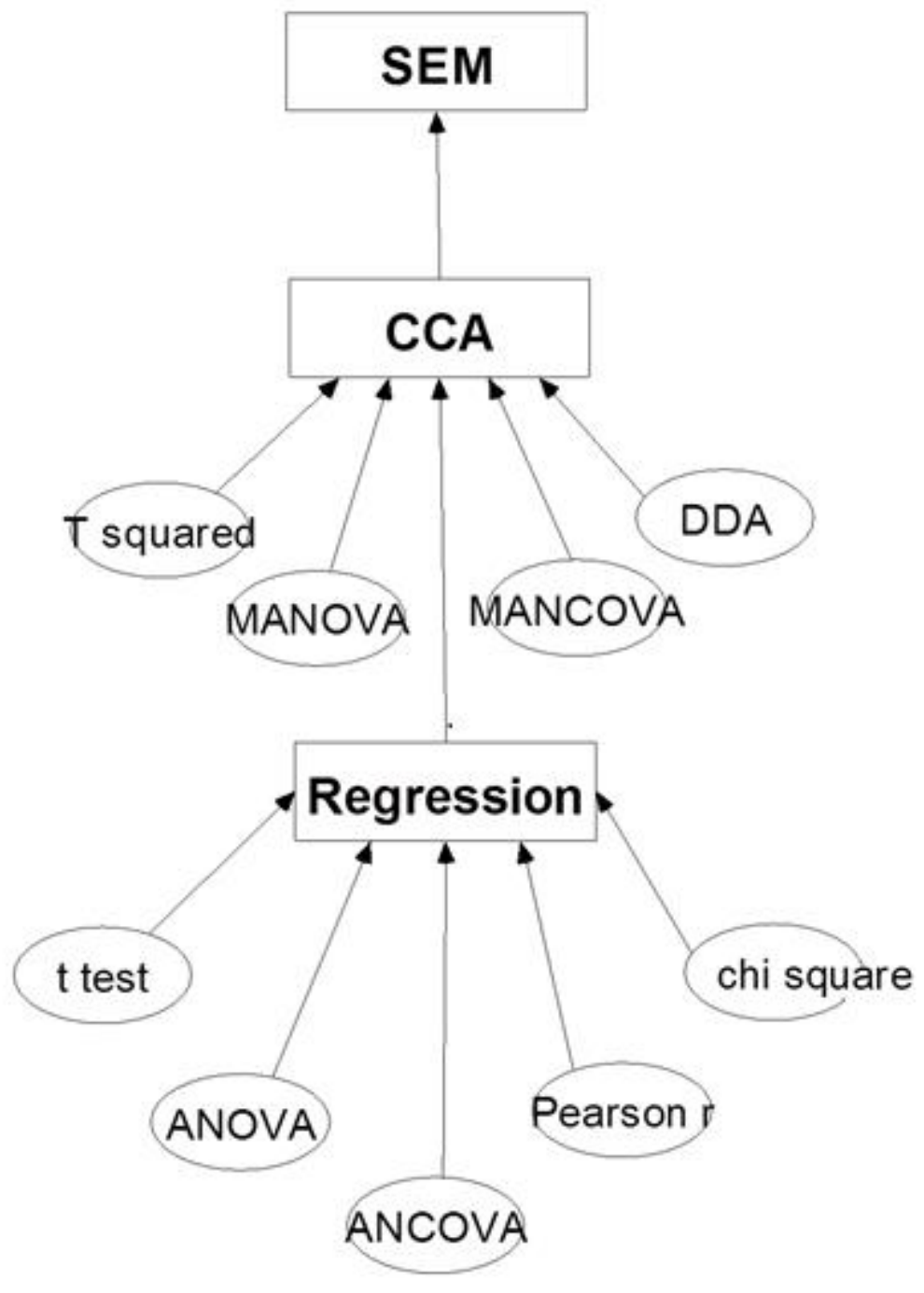

Note. Descriptive discriminant analysis (DDA) is part of the general linear model, but predictive discriminant analysis (PDA) is not part of the GLM. "SEM" = structural equation modeling; "CCA" = canonical correlation analysis; " $T$-squared" = Hotelling's $T^{2}$, a multivariate extension of the $t$-test to multiple dependent variables.

A very powerful way to prove to students that CCA subsumes other multivariate and univariate parametric methods is to use "proof by SPSS." That is, some students assume that SPSS was written by God, and that therefore anything on an SPSS output must be infallibly true. Here I use the Appendix A heuristic data and the Appendix B SPSS syntax to perform a couple of these proofs via SPSS. 


\section{CCA Subsumes Regression as a Special Case}

Figure 2 presents a cut-and-paste copy out of an SPSS output for a regression analysis predicting IQ scores with predictors $\mathrm{X} 1, \mathrm{X} 2$, and $\mathrm{X}_{3}$. Figure 3 presents a cut-and-paste copy out of an SPSS output for a CCA with the same measured variables. Note that the regression $R^{2}=.04106$ equals the $\mathrm{CCA} R_{\mathrm{C}}=.041$.

Figure 2. Cut-and-Paste Copy of SPSS (version 6) Output Regression with IQ as Outcome Variable and Variables $\mathrm{X}_{1}, \mathrm{X}_{2}$ and $\mathrm{X}_{3}$ as Predictors

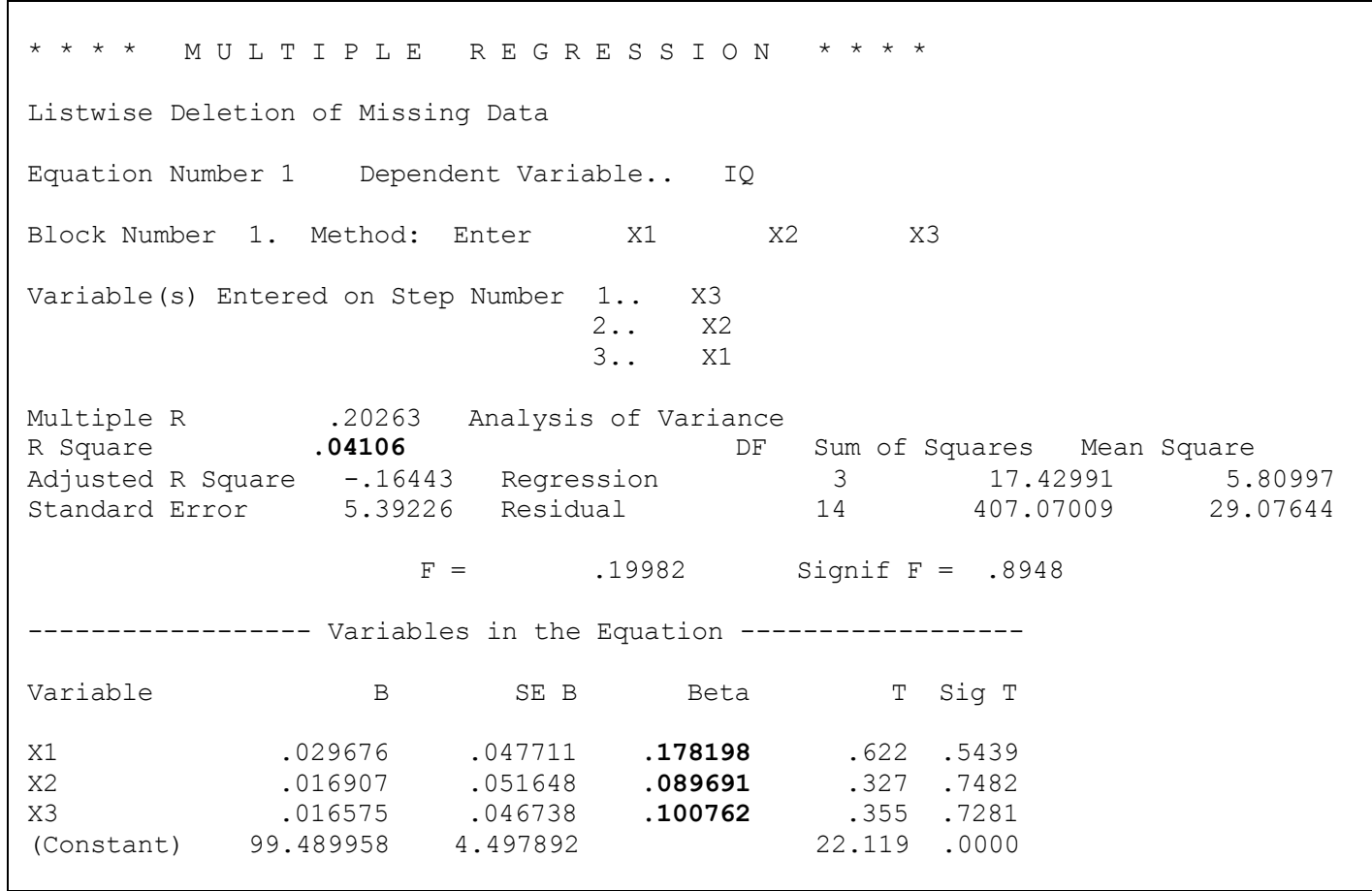

Figure 3. Cut-and-Paste Copy of SPSS (version 6) Output CCA with IQ as Predictor Variable and Variables $\mathrm{X}_{1}, \mathrm{X}_{2}$ and $\mathrm{X}_{3}$ as Outcomes

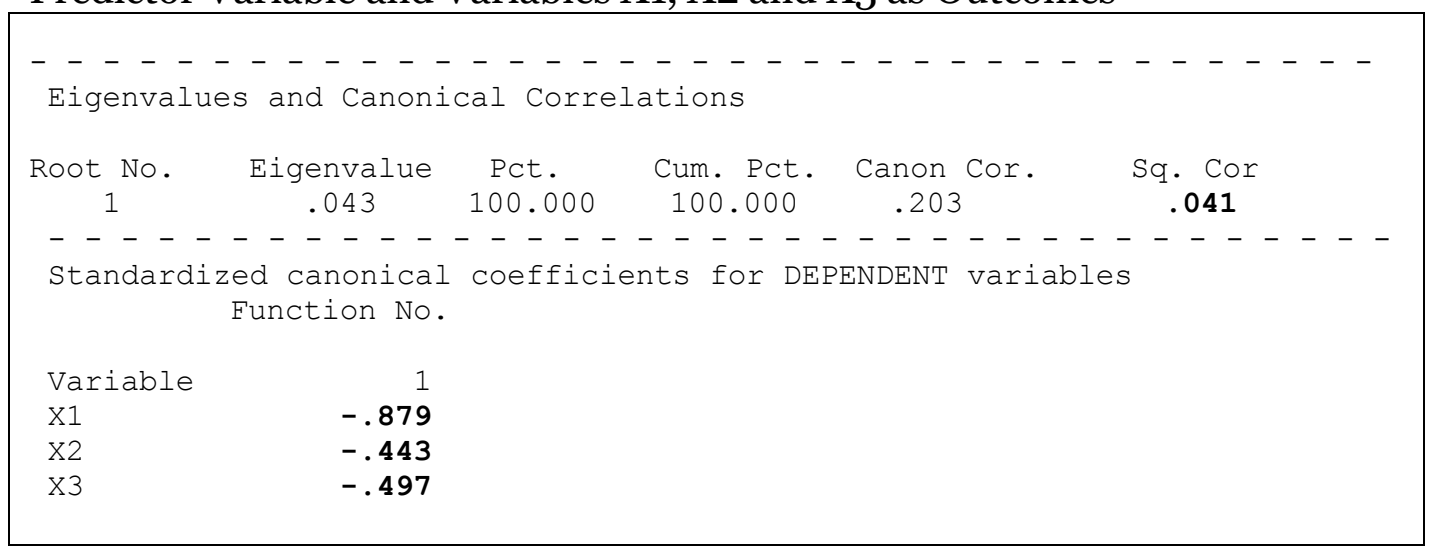


However, at first glance the regression beta weights do not appear to match the CCA standardized function coefficients for the parallel analysis. First, the CCA function coefficients each have a different sign than the three regression beta weights! But the scaling direction of equations is purely arbitrary, and any researcher can at will reverse all the signs in an equation within the GLM (see Thompson, 2004, pp. 96-97). This is the equivalent of the arbitrary choice of whether to score a test by counting number of right answers versus number of wrong answers.

Second, the scaling of the regression beta weights and the CCA function coefficients is different. Table 1 illustrates how the two sets of weights can be converted into each other's metrics.

Table 1

Converting Beta Weights into CCA Function Coefficients, and Vice Versa

\begin{tabular}{lcccc}
\hline Variable & Beta $/ R_{\mathrm{C}}$ & Function Coefs. & $R$ \\
\hline $\mathrm{X} 1$ & $0.178198 / 0.203=$ & 0.879 & $* 0.20263$ \\
$\mathrm{X} 2$ & $0.089691 / 0.203=$ & 0.443 & $* 0.20263$ \\
$\mathrm{X}_{3}$ & $0.100762 / 0.203=$ & 0.497 & $* 0.20263$ \\
\hline
\end{tabular}

\section{CCA Subsumes Multi-Way ANOVA as a Special Case}

Figure 4 presents a cut-and-paste copy out of an SPSS output for an ANOVA summary table for an analysis into IQ as the dependent variable in a two-way factorial ANOVA. Conducting the parallel ANOVA using CCA is a bit

Figure 4. Cut-and-Paste Copy of SPSS (version 6) Output ANOVA with IQ as Outcome Variable and Variables $\mathrm{X}_{1}, \mathrm{X}_{2}$ and $\mathrm{X}_{3}$ as Predictor Variables

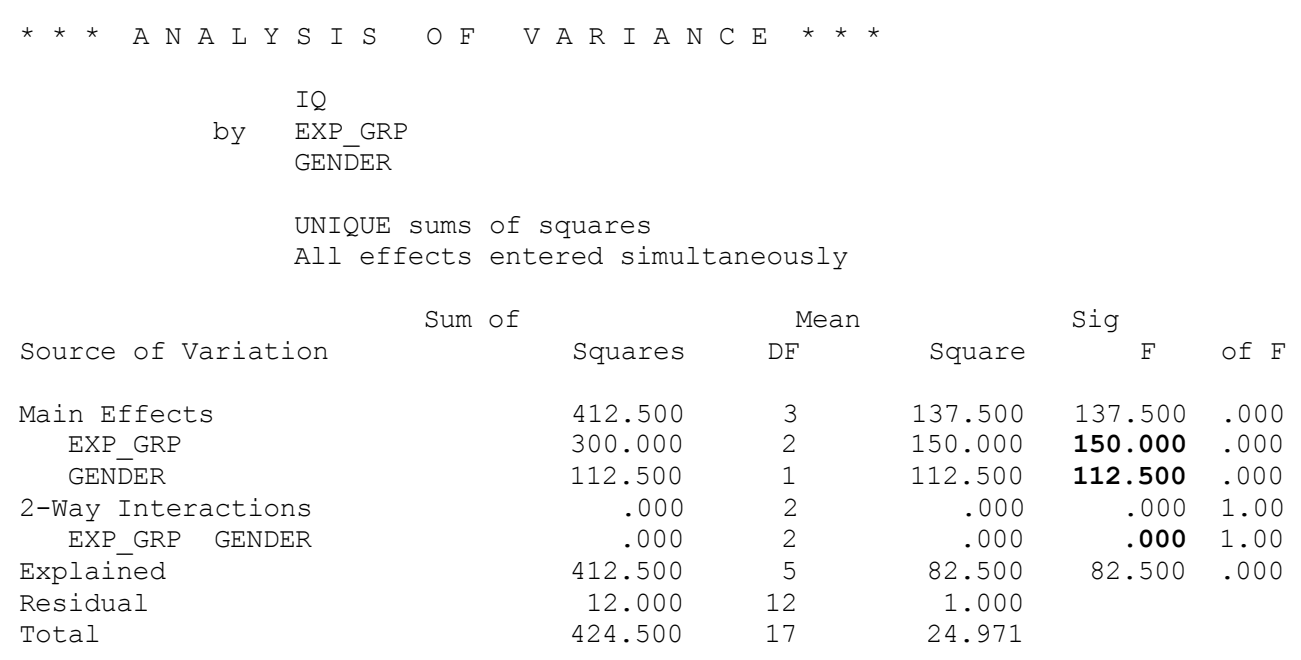


tedious, but otherwise is not problematic. First, create orthogonal contrasts using conventional methods explained in various textbooks (e.g., Thompson, 2006). Next, run a CCA model using all the contrast variables. Then run CCA models dropping in turn the contrast variables for the three omnibus effects. Figure 5 presents cut-and-paste copies out of an SPSS output for these analyses.

Figure 5. Cut-and-Paste Copy of SPSS (version 6) Output CCAs with IQ as IQ as Outcome Variable and Variables $\mathrm{X}_{1}, \mathrm{X}_{2}$ and $\mathrm{X}_{3}$ as Predictor Variables.

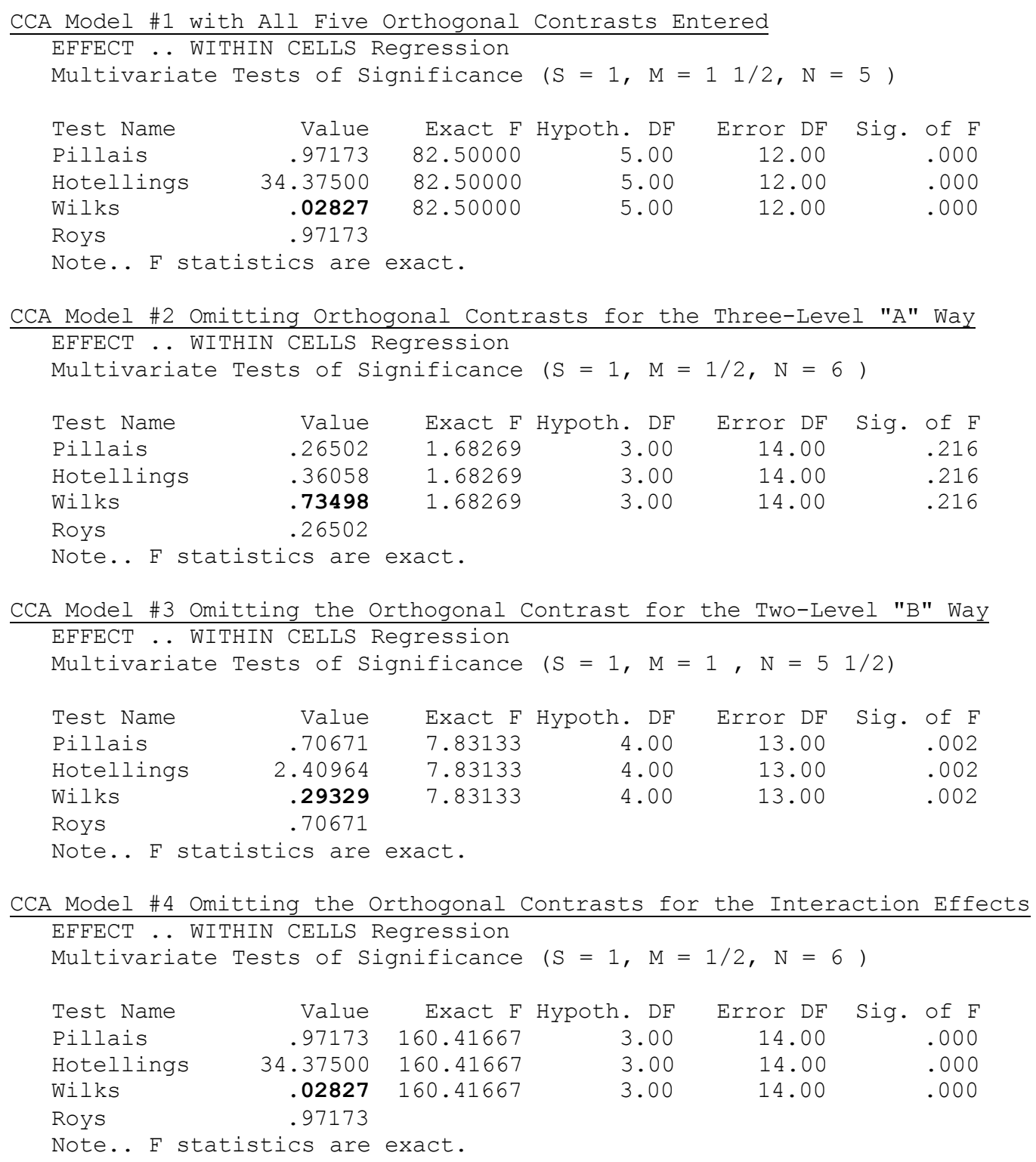


Tables 2 and 3 present the calculations to convert CCA lambda values back into conventional ANOVA $F_{\text {CALCULATED values. Obviously, one would not }}$ routinely perform ANOVA using CCA, but nevertheless the point that CCA is the multivariate GLM has hopefully been made!

Table 2

Step \#1 in Converting CCA Results into Conventional ANOVA $F_{C A L C U L A T E D}$ Values: Running Full and Restricted Models for the Various ANOVA Omnibus Effects

\begin{tabular}{llllllr}
\hline & Model & Predictors & & & & $\begin{array}{c}\text { CCA } \\
\text { lambda }\end{array}$ \\
\hline 1 & A1 & A2 & B1 & A1B1 & A2B1 & 0.02827 \\
2 & & & B1 & A1B1 & A2B1 & 0.73498 \\
3 & A1 & A2 & & A1B1 & A2B1 & 0.29329 \\
4 & A1 & A2 & B2 & & & 0.02827 \\
\hline
\end{tabular}

Table 3

Step \#2: Converting CCA lambda into Ratios into Classical ANOVA $F_{\text {CALCULATED Values }}$

\begin{tabular}{lllll}
\hline Effect & Ratio & $\begin{array}{l}\text { Full Mode } \\
\text { lambda }\end{array}$ & $\begin{array}{l}\text { Lambda } \\
\text { w/o effect }\end{array}$ & Ratio \\
\hline A Way & $1 / 2$ & 0.02827 & 0.73498 & 0.03846 \\
B Way & $1 / 3$ & 0.02827 & 0.29329 & 0.09639 \\
AxB Interaction & $1 / 4$ & 0.02827 & 0.02827 & 1.00000 \\
\hline
\end{tabular}

\section{Reasons Why I Advocate Teaching Statistics and Psychometrics from a GLM Perspective}

Here are some of the reasons why I advocate teaching both statistics and psychometrics from a GLM perspective:

1. Teaching statistics and psychometrics from a GLM perspective helps students understand that sampling error effects both $p_{\text {_CALCULATED }}$ values and effect sizes no matter what analysis is being done.

2. Teaching statistics and psychometrics from a GLM perspective helps students understand that weights are applied to measured variables to estimate latent variables in every analysis. For example, in a balanced ANOVA the eta values are also the beta weights for estimating Y-hat values in ANOVA (see Thompson, 2006).

3. Teaching statistics and psychometrics from a GLM perspective helps students understand that it is the design, and not the analysis, that 
provides the ability to make causal claims (see Thompson, 2006, chapter 12).

4. Teaching statistics and psychometrics from a GLM perspective helps students understand that statistics and psychometric models do the same things, albeit it for different purposes: they partition variances (or sum of squares) and estimate ratios of those partitions in forms such as eta squared, $R_{2}, R_{\mathrm{C} 2}$, and reliability coefficients (see Dawson, 1999).

5. Teaching statistics and psychometrics from a GLM perspective helps students understand that all analyses are correlation, which among other things implies that all analyses can be conducted without a researcher's data, as long as one has the covariance matrix and means and $S D$ s. These summary statistics are perfectly suitable as inputs into SPSS analyses (see Zientek \& Thompson, 2009).

Author Notes: Correspondence concerning this article should be addressed to Bruce Thompson at bruce-thompson@tamu.edu.

\section{References}

Bagozzi, R.P., Fornell, C., \& Larcker, D.F. (1981). Canonical correlation analysis as a special case of a structural relations model. Multivariate Behavioral Research, $16,437-454$.

Cohen, J. (1968). Multiple regression as a general data-analytic system. Psychological Bulletin, 70, 426-433.

Dawson, T.E. (1999). Relating variance partitioning in measurement analyses to the exact same process in substantive analyses. In B. Thompson (Ed.), Advances in social science methodology (Vol. 5, pp. 101-110). Stamford, CT: JAI Press.

Edgington, E.S. (1964). A tabulation of inferential statistics used in psychology journals. American Psychologist, 19, 202-203.

Edgington, E.S. (1974). A new tabulation of statistical procedures used in APA journals. American Psychologist, 29, 25-26.

Elmore, P.B., \& Woehlke, P.L. (1988). Statistical methods employed in American Educational Research Journal, Educational Researcher, and Review of Educational Research from 1978 to 1987. Educational Researcher, 17(9), 19-20.

Fan, X. (1997). Canonical correlation analysis and structural equation modeling: What do they have in common? Structural Equation Modeling, 4, 65-79.

Goodwin, L.D., \& Goodwin, W.L. (1985). Statistical techniques in AERJ articles, 1979-1983: The preparation of graduate students to read the educational research literature. Educational Researcher, 14(2), 5-11.

Graham, J. M. (2008). The General Linear Model as structural equation modeling. Journal of Educational and Behavioral Statistics, 33, 485-506.

Huberty, C. (1994). Applied discriminant analysis. New York: Wiley and Sons. 


\section{THOMPSON}

Kieffer, K. M., Reese, R. J., \& Thompson, B. (2001). Statistical techniques employed in AERJ and JCP articles from 1988 to 1997: A methodological review. Journal of Experimental Education, 69, 280-309.

Knapp, T. R. (1978). Canonical correlation analysis: A general parametric significance testing system. Psychological Bulletin, 85, 410-416.

Thompson, B. (1984). Canonical correlation analysis: Uses and interpretations. Thousand Oaks, CA: Sage.

Thompson, B. (2000). Canonical correlation analysis. In L. Grimm \& P. Yarnold (Eds.), Reading and understanding more multivariate statistics (pp. 285-316). Washington, DC: American Psychological Association.

Thompson, B. (2004). Exploratory and confirmatory factor analysis: Understanding concepts and applications. Washington, DC: American Psychological Association.

Thompson, B. (2006). Foundations of behavioral statistics: An insight-based approach. New York: Guilford.

Willson, V. L. (1980). Research techniques in AERJ articles: 1969 to 1978. Educational Researcher, 9(6), 5-10.

Zientek, L.R., \& Thompson, B. (2009). Matrix summaries improve research reports: Secondary analyses using published literature. Educational Researcher, 38, 343-352. 


\section{Appendix A \\ Hypothetical Heuristic Data}

$\begin{array}{rrrrrrrr}1 & 1 & 1 & 94 & 790 & 12 & 41 & 14 \\ 2 & 1 & 1 & 95 & 795 & 51 & 6 & 88 \\ 3 & 1 & 1 & 96 & 800 & 79 & 99 & 32 \\ 4 & 1 & 2 & 99 & 780 & 9 & 16 & 79 \\ 5 & 1 & 2 & 100 & 785 & 60 & 33 & 14 \\ 6 & 1 & 2 & 101 & 790 & 97 & 30 & 3 \\ 7 & 2 & 1 & 99 & 785 & 28 & 64 & 90 \\ 8 & 2 & 1 & 100 & 790 & 46 & 64 & 12 \\ 9 & 2 & 1 & 101 & 795 & 2 & 23 & 84 \\ 10 & 2 & 2 & 104 & 775 & 28 & 7 & 31 \\ 11 & 2 & 2 & 105 & 780 & 84 & 21 & 66 \\ 12 & 2 & 2 & 106 & 785 & 10 & 73 & 47 \\ 13 & 3 & 1 & 104 & 800 & 65 & 83 & 39 \\ 14 & 3 & 1 & 105 & 795 & 75 & 59 & 65 \\ 15 & 3 & 1 & 106 & 790 & 96 & 69 & 17 \\ 16 & 3 & 2 & 109 & 770 & 45 & 53 & 91 \\ 17 & 3 & 2 & 110 & 775 & 47 & 48 & 29 \\ 18 & 3 & 2 & 111 & 780 & 48 & 42 & 41\end{array}$




\section{THOMPSON}

\section{Appendix B SPSS Syntax File for the Illustrative Example}

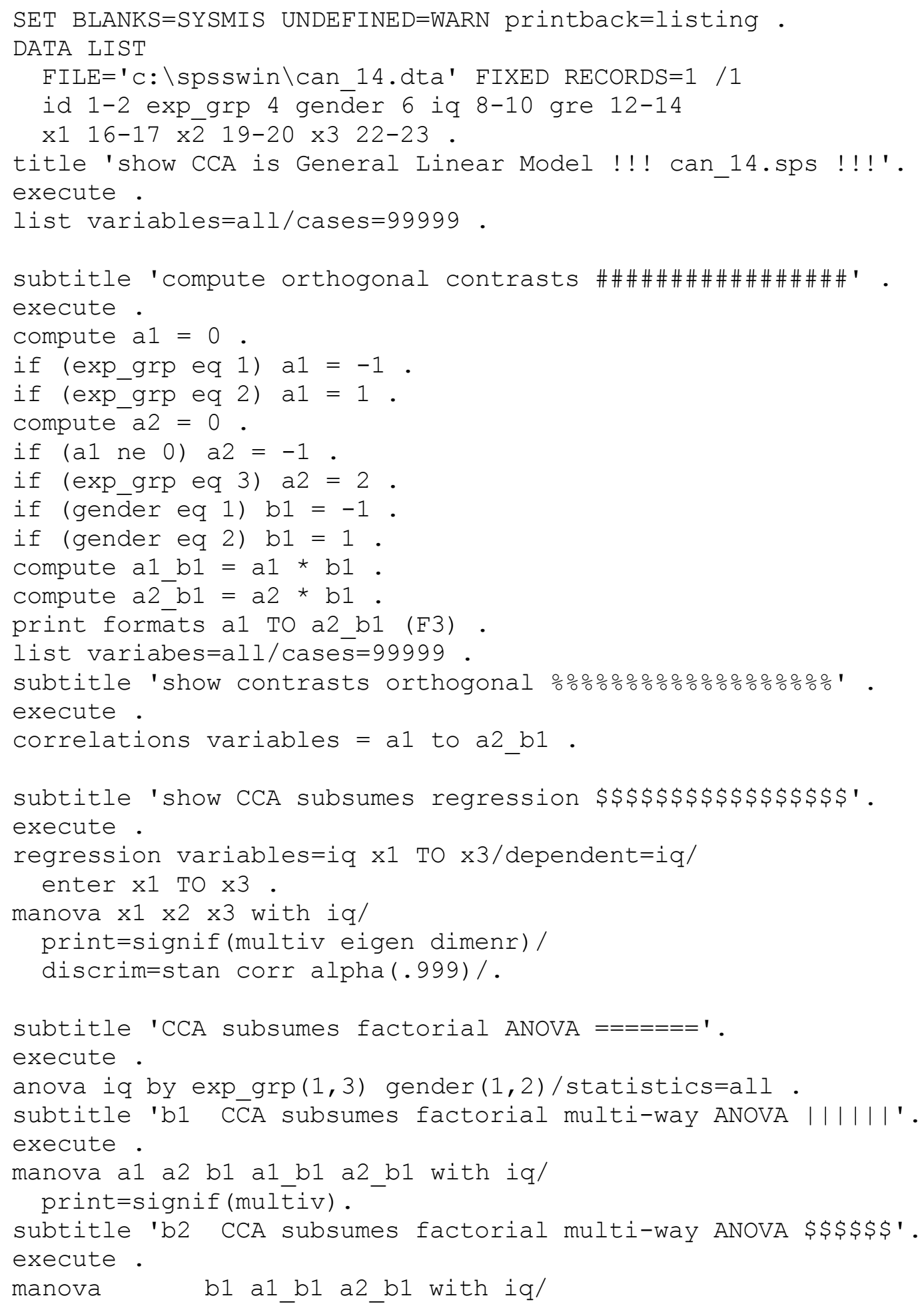




\section{TEACHING USING THE GLM}

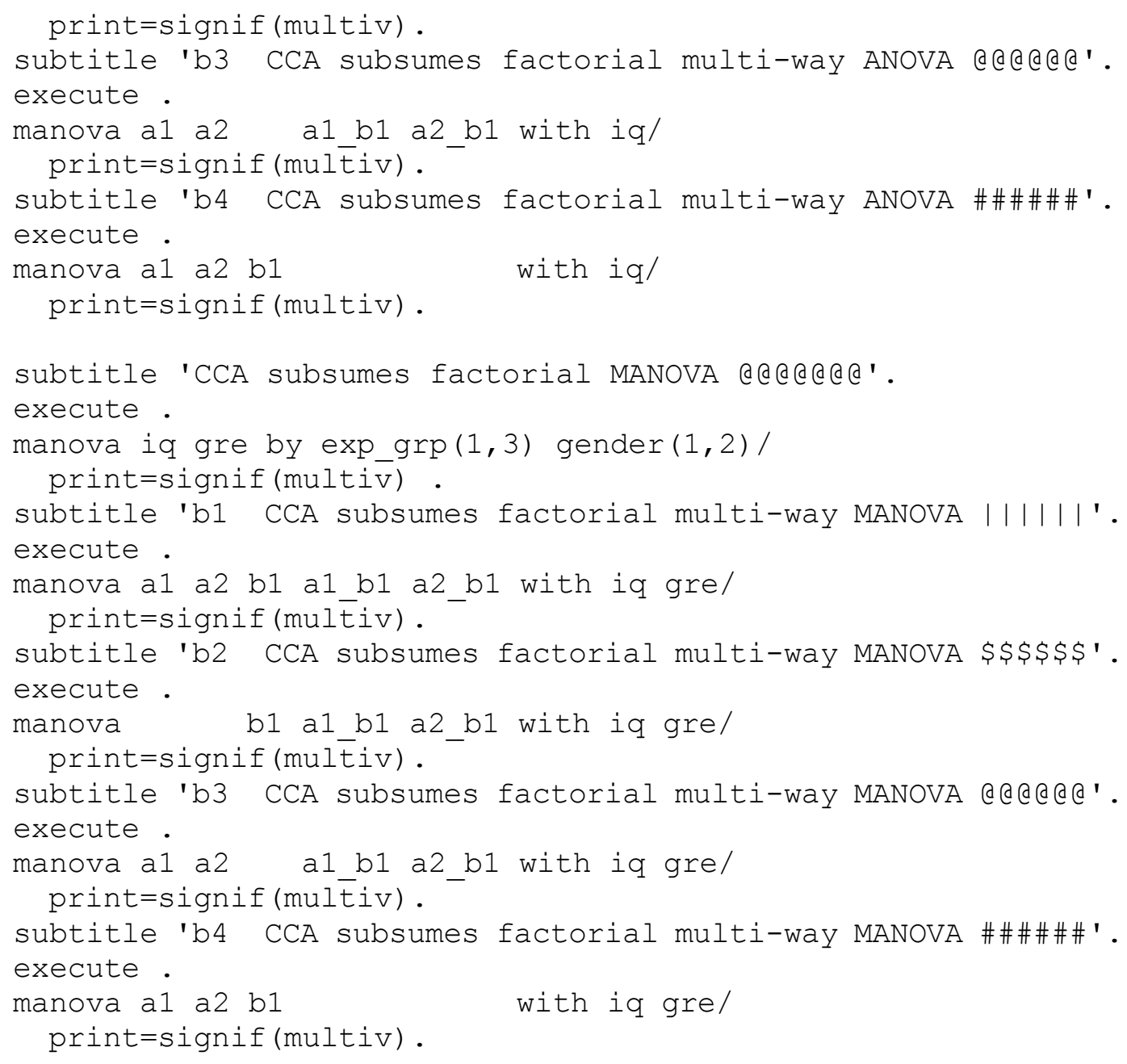

